\title{
RECOVERY OF NATURAL ANTIOXIDANTS FROM FRUIT JUICE INDUSTRY RESIDUALS BY ULTRASOUND-ASSISTED EXTRACTION AND RESPONSE SURFACE METHODOLOGY
}

\author{
R. Tabaraki*, E. Heidarizadi, N. Sadeghinezhad, S. Salimpour and Z. Yosefi \\ Department of Chemistry, Faculty of Science, Ilam University, Pajoohesh Street, Ilam. Iran
}

(Received: 14 May 2014; accepted: 24 November 2014)

\begin{abstract}
Fruit processing industries produce by-products that are good sources of natural antioxidants. These residuals are non-toxic and available in large quantities. A central composite design (CCD) and response surface methodology (RSM) were used to optimize experimental conditions. The processing variables were solvent type, solvent to solid ratio, ethanol concentration, temperature, and time. The responses were total phenolic content (TPC), scavenging activity of 2,2-diphenyl-1-picrylhydrazyl (DPPH) radical, and yield. The optimal conditions were $70 \%$ ethanolwater mixture as a food grade solvent, temperature of $35^{\circ} \mathrm{C}$ and extraction time $60 \mathrm{~min}$ for obtaining extracts with maximum of total phenolic content. Predicted values for total phenolic content in pear, apricot, and peach were 24.7, 19.3 , and $10.4 \mathrm{mg}$ gallic acid equivalents per $100 \mathrm{~g}$ fruit residual, respectively.

Keywords: antioxidants, pear, peach, apricot, ultrasound extraction, response surface methodology
\end{abstract}

The oxidative stress imposed by reactive oxygen species (ROS) plays an important role in many chronic and degenerative diseases (FInKel \& Holbrook, 2000). High intake of fruit and vegetables can provide the antioxidants, trace minerals, and other bioactive compounds to counter oxidative stress. The growing interest in the substitution of synthetic food antioxidants by natural ones has fostered on vegetable sources.

Due to the perishable nature of fruit (such as pear, peach, and apricot) and restricted marketing chance, a large proportion of these fruit is wasted during harvesting season and the losses are as higher as $29 \%$ of total fresh production. Each year, more than 1.5, 1.5, and 2.8 million tons of peach, apricot, and pear are produced in Iran, respectively (http://dbagri.maj. $\mathrm{ir} / \mathrm{zrt}$ /product.asp). The desirable taste, high digestibility, and delightful aroma of pear (Pyrus communis L.), peach (Prunus persica L.), and apricot (Prunus armeniaca) make them very popular among consumers (Solis-Solis et al., 2007; SALTA et al., 2010). Phenolic compounds, such as chlorogenic acid, caffeic acid, p-coumaroyl quinic and p-coumaric acids, and procyanidin and quercetin, have been reported in pear (SCHIEBER et al., 2001). Phenolics and carotenoids are natural antioxidants of peach that possess beneficial properties for human health (Oliveira et al., 2012). Apricot is a natural antioxidant source of vitamin A, vitamin C, polyphenols, flavonoids, and carotenoids.

The extraction of bioactive compounds under ultrasound irradiation $(20-100 \mathrm{kHz})$ is one of the upcoming extraction techniques that can offer shorter operation times, simplified manipulation, lower energy input, and reduced solvent consumption and temperature. Hence, ultrasound-assisted extraction (UAE) can be called an "environment-friendly" or "green" technique (VIrOT et al., 2010). The efficiency of the extraction process is affected by several

\footnotetext{
* To whom correspondence should be addressed.

Phone: 98-841-2227022; fax: 98-841-2227022; e-mails: rezatabaraki@yahoo.com; r.tabaraki@ilam.ac.ir
} 
factors, such as solvent type and its concentration, solvent to solid ratio, contact time, temperature, and particle size of the sample matrix. When many factors and interactions affect desired process response, response surface methodology is an effective tool for optimizing the process. RSM is a collection of statistical and mathematical techniques that has been successfully used to determine the effects of several variables and optimize processes (BEZERRA et al., 2008).

The aim of this study was to optimize experimental conditions for ultrasound-assisted extraction of natural antioxidants from pear, peach, and apricot residuals by response surface methodology. Till now, UAE has not been used for recovery of antioxidants from these residuals.

\section{Materials and methods}

\subsection{Plant materials}

Fruit (pear, peach, and apricot) were purchased from local markets in Ilam, Iran. Fruit were washed with distilled water and then cut into small pieces. Fruit pieces were introduced in an electrical juicer (Pars Khazar, Rasht, Iran) to obtain juice and the residuals were separated. The residuals were maintained at $-20^{\circ} \mathrm{C}$ in vacuum packages.

\subsection{Chemicals}

2,4,6-tris (2-pyridyl)-s-triazine (TPTZ), Folin-Ciocalteu (FC) reagent and gallic acid were purchased from Merck (Darmstadt, Germany). 2,2-diphenyl-1-picrylhydrazyl (DPPH) was purchased from Sigma-Aldrich (Munich, Germany). All reagents were of analytical grade.

\subsection{Extraction procedure}

The process of polyphenols and antioxidants extraction from pear, peach, and apricot residuals by ultrasonic was performed in an ultrasonic bath RK103H (Bandelin Sonorex, Berlin, Germany) with a maximum capacity of $41(35 \mathrm{KHz}, 140 \mathrm{~W})$. Sample $(5 \mathrm{~g})$ was sonicated in the solvent $(5 \mathrm{ml})$ for different times and at different temperatures. Then, the extract was centrifuged at 4500 r.p.m. for $10 \mathrm{~min}$. The extracts were concentrated by rotary evaporation at $40{ }^{\circ} \mathrm{C}$ under vacuum to dryness and the yield of extraction was determined.

\subsection{Optimization of solvent and solvent to solid}

In this study, several extraction solvents, such as methanol, ethanol, water, and acetone, were used to study a wide range of polarity of antioxidants. The extraction of antioxidant was performed in ultrasonic bath over a $30 \mathrm{~min}$ extraction period at $50{ }^{\circ} \mathrm{C}$.

A second set of tests was performed for the selection of appropriate solvent to solid ratio $(\mathrm{ml}: \mathrm{g})$ to extract the phenolic compounds from fruit residuals. The extraction was carried out using $5 \mathrm{ml}$ of ethanol solution ( $50 \%$ ethanol:water; $\mathrm{v} / \mathrm{v})$ and different weights $(1,2,4,5$, and $7 \mathrm{~g}$ ) of residuals (solvent to solid ratios: $5,2.5,1.25,1$, and 0.7 ). The extraction of antioxidants was performed in ultrasonic bath over a $30 \mathrm{~min}$ extraction period at $50{ }^{\circ} \mathrm{C}$.

\subsection{Total phenolic content}

Total phenolic content (TPC) of the extracts were determined using Folin-Ciocalteu (FC) reagent (Singleton \& Rossi, 1965). Forty microlitres of properly diluted extract solution 
were mixed with $1.8 \mathrm{ml}$ of FC reagent. The reagent was pre-diluted, 10 times, with distilled water. After standing for $5 \mathrm{~min}$ at room temperature, $1.2 \mathrm{ml}$ of $(7.5 \%, \mathrm{w} / \mathrm{v})$ sodium carbonate solution was added. The solution were mixed and allowed to stand for $1 \mathrm{~h}$ at room temperature. Then, the absorbance was measured at $765 \mathrm{~nm}$ using a UV-Visible spectrophotometer (Varian 300, Mulgrave, Australia). The results of total phenolic content were expressed as mg gallic acid equivalents per $100 \mathrm{~g}$ of residuals.

\subsection{Scavenging activity of DPPH radical}

DPPH radical-scavenging activity of residual extract was determined according to the method reported by BRAND-WILLIAMS and co-workers (1995), with some modification. An aliquot of $0.5 \mathrm{ml}$ of sample solution was mixed with $2.5 \mathrm{ml}$ of a methanolic solution of DPPH $(0.5 \mathrm{mM})$. The mixture was shaken vigorously and incubated for $30 \mathrm{~min}$ in the dark at room temperature. The absorbance was measured at $517 \mathrm{~nm}$ against a blank, using a UV-Vis spectrophotometer. Results were expressed as percentage of inhibition of the DPPH radical. Percentage of inhibition of the DPPH radical was calculated according to the following equation:

$$
\% \text { Inhibition of DPPH }=\left(\frac{\mathrm{Abs}_{\text {control }}-\mathrm{Abs}_{\text {sample }}}{\mathrm{Abs}_{\text {control }}}\right) \times 100
$$

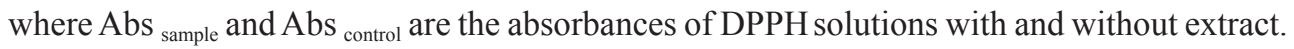

\subsection{Experimental design and central composite design}

Three factors that can potentially affect extraction of antioxidants, such as ethanol percentage $\left(\mathrm{X}_{1}, \%\right)$, extraction temperature $\left(\mathrm{X}_{2},{ }^{\circ} \mathrm{C}\right)$, and extraction time $\left(\mathrm{X}_{3}, \mathrm{~min}\right)$, were chosen as key variables. The minimum and maximum levels to each factor were chosen based on preliminary experiments, our experience, and that of our previous works. A version of central composite design, face centre cube with the star points at the centre of each face of the factorial space $(\alpha= \pm 1)$, was used to identify the relationship between three independent factors and the dependent variables or responses. The design had 16 runs and each run was performed in triplicates. Centre point (run 15 and 16) was replicated to have a measurement of reproducibility and to model lack of fit. The factors (ethanol concentration, temperature, and time) were set at three separate coded levels, $-1,0$, and +1 . The total phenolic content TPC $\left(\mathrm{Y}_{1}\right)$, DPPH scavenging activity $\left(\mathrm{Y}_{2}\right)$, and extraction yield $\left(\mathrm{Y}_{3}\right)$ were chosen as the dependent variables.

The complete quadratic equation used is as follows:

$$
\mathrm{Y}=\beta_{\mathrm{o}}+\sum_{i=1}^{3} \beta_{\mathrm{i}} \mathrm{X}_{\mathrm{i}}+\sum_{\mathrm{i}}^{3} \beta_{\mathrm{ii}} \mathrm{X}_{\mathrm{i}}^{2}+\sum_{\mathrm{i}=1}^{2} \sum_{j=\mathrm{i}+1}^{3} \beta_{\mathrm{ij}} \mathrm{X}_{\mathrm{i}} \mathrm{Y}_{\mathrm{j}}
$$

where $Y$ is the estimated response; $\beta_{\mathrm{o}}, \beta_{\mathrm{i}}, \beta_{\mathrm{ii}}$, and $\beta_{\mathrm{ij}}$ are the regression coefficients for intercept, linear, square, and interaction terms, respectively; and $\mathrm{X}_{\mathrm{i}}$ and $\mathrm{X}_{\mathrm{j}}$ are the independent variables. 
All the analysis was carried out in triplicates and the experimental results were expressed as mean \pm SD. Statistical analysis was performed by using the Minitab 15.1 (Minitab Inc., State College, PA, USA) software.

\section{Results and discussion}

\subsection{Effect of solvent}

Several solvents were used and results are shown in Table 1. The results show that ethanolic extracts exhibited the highest TPC, DPPH, and extraction yield. Environmentally benign and non-toxic food grade organic solvents, like water and ethanol, are also recommended by the US food and drug administration for extraction purposes (BARTNIK et al., 2006). So ethanolwater mixture was chosen as the extraction solvent for the next experiments.

Table 1. Effect of solvent on the TPC, DPPH, and extraction yield

\begin{tabular}{|c|c|c|c|c|}
\hline \multirow[t]{2}{*}{ Solvent } & \multirow[t]{2}{*}{ Fruits } & \multicolumn{3}{|c|}{ Responses } \\
\hline & & TPC & DPPH & Yield \\
\hline \multirow{3}{*}{ Methanol } & Pear & $15.0 \pm 0.6$ & $50.1 \pm 1.9$ & $2.9 \pm 0.1$ \\
\hline & Peach & $6.4 \pm 0.2$ & $66.4 \pm 2.4$ & $5.3 \pm 0.3$ \\
\hline & Apricot & $18.0 \pm 0.8$ & $78.8 \pm 2.7$ & $6.8 \pm 0.4$ \\
\hline \multirow{3}{*}{ Ethanol } & Pear & $18.7 \pm 0.7$ & $59.8 \pm 2.1$ & $4.8 \pm 0.2$ \\
\hline & Peach & $7.9 \pm 0.3$ & $72.3 \pm 2.2$ & $6.2 \pm 0.4$ \\
\hline & Apricot & $19.5 \pm 0.6$ & $85.5 \pm 3.3$ & $7.4 \pm 0.4$ \\
\hline \multirow{3}{*}{ Water } & Pear & $12.0 \pm 0.6$ & $44.9 \pm 1.4$ & $2.1 \pm 0.1$ \\
\hline & Peach & $4.2 \pm 0.2$ & $60.2 \pm 1.9$ & $3.4 \pm 0.2$ \\
\hline & Apricot & $15.2 \pm 0.6$ & $70.4 \pm 3.6$ & $3.2 \pm 0.2$ \\
\hline \multirow{3}{*}{ Aceton } & Pear & $17.2 \pm 0.7$ & $54.0 \pm 1.8$ & $3.8 \pm 0.3$ \\
\hline & Peach & $6.6 \pm 0.4$ & $70.3 \pm 2.9$ & $5.0 \pm 0.3$ \\
\hline & Apricot & $17.4 \pm 0.7$ & $80.2 \pm 3.8$ & $6.3 \pm 0.3$ \\
\hline
\end{tabular}

TPC (mg gallic acid equivalents/100 g pomace); DPPH (\% inhibition)

\subsection{Effect of solvent to solid ratio}

The TPC, DPPH, and extraction yield under different solvent to solid ratios were investigated. The solvent to solid ratio varied from 0.7:1 to 5:1 (Table 2). As shown, the best results were obtained for solvent to solid ratio of 1 for all responses. Therefore, the solvent to solid ratio of 1 was used for further experiments. 
Table 2. Effect of solvent to solid ratio on the TPC, DPPH, and extraction yield

\begin{tabular}{|c|c|c|c|c|}
\hline \multirow{2}{*}{$\begin{array}{l}\text { Solvent to } \\
\text { solid ratio }\end{array}$} & \multirow[t]{2}{*}{ Fruits } & \multicolumn{3}{|c|}{ Responses } \\
\hline & & $\mathrm{TPC}$ & DPPH & Yield \\
\hline \multirow{3}{*}{5} & Pear & $13.1 \pm 0.7$ & $29.3 \pm 1.3$ & $2.0 \pm 0.1$ \\
\hline & Peach & $2.5 \pm 0.1$ & $48.5 \pm 2.3$ & $2.8 \pm 0.1$ \\
\hline & Apricot & $8.2 \pm 0.4$ & $61.7 \pm 3.4$ & $3.0 \pm 0.2$ \\
\hline \multirow{3}{*}{2.5} & Pear & $15.2 \pm 0.7$ & $34.2 \pm 1.4$ & $3.4 \pm 0.2$ \\
\hline & Peach & $3.8 \pm 0.2$ & $58.1 \pm 2.8$ & $3.9 \pm 0.2$ \\
\hline & Apricot & $11.8 \pm 0.5$ & $68.2 \pm 3.5$ & $4.5 \pm 0.2$ \\
\hline \multirow{3}{*}{1.25} & Pear & $19.3 \pm 0.9$ & $48.4 \pm 2.5$ & $4.6 \pm 0.3$ \\
\hline & Peach & $5.2 \pm 0.2$ & $62.4 \pm 3.3$ & $5.2 \pm 0.3$ \\
\hline & Apricot & $14.1 \pm 0.6$ & $74.8 \pm 4.2$ & $6.4 \pm 0.4$ \\
\hline \multirow{3}{*}{1} & Pear & $19.9 \pm 1.1$ & $49.1 \pm 1.9$ & $4.7 \pm 0.2$ \\
\hline & Peach & $7.5 \pm 0.4$ & $69.8 \pm 4.1$ & $6.4 \pm 0.4$ \\
\hline & Apricot & $16.3 \pm 0.7$ & $80.1 \pm 3.9$ & $7.8 \pm 0.4$ \\
\hline \multirow{3}{*}{0.7} & Pear & $19.8 \pm 1.0$ & $48.9 \pm 2.6$ & $4.8 \pm 0.3$ \\
\hline & Peach & $7.4 \pm 0.3$ & $69.2 \pm 3.7$ & $6.0 \pm 0.3$ \\
\hline & Apricot & $16.2 \pm 0.7$ & $80.2 \pm 4.4$ & $7.27 \pm 0.3$ \\
\hline
\end{tabular}

TPC (mg gallic acid equivalents/100 g pomace); DPPH (\% inhibition)

\subsection{Modelling of the extraction process and effect of process variables}

The responses (TPC, DPPH scavenging activity, and extraction yield) of each run of the experimental design, coded and decoded values of independent variables are presented in Table 3. The second-order polynomial equation of models for total phenolic content, antioxidant activity of extracts, and yield are summarized in Table 4 . The large values of the $\mathrm{R}^{2}$ reveal that the models adequately represent the experimental results. As shown, the regression parameters of the surface response analysis of the models, the linear, quadratic, and interaction terms have significant effects $(\mathrm{P} \leq 0.001, \mathrm{P} \leq 0.01$, or $\mathrm{P} \leq 0.05)$. The absence of any lack of fit $(\mathrm{P}>0.05)$ also strengthened the reliability of all models.

The effects of ethanol concentration, temperature, and time on extraction yield for residuals of pear, peach, and apricot are shown in Figures 1-3, respectively. 


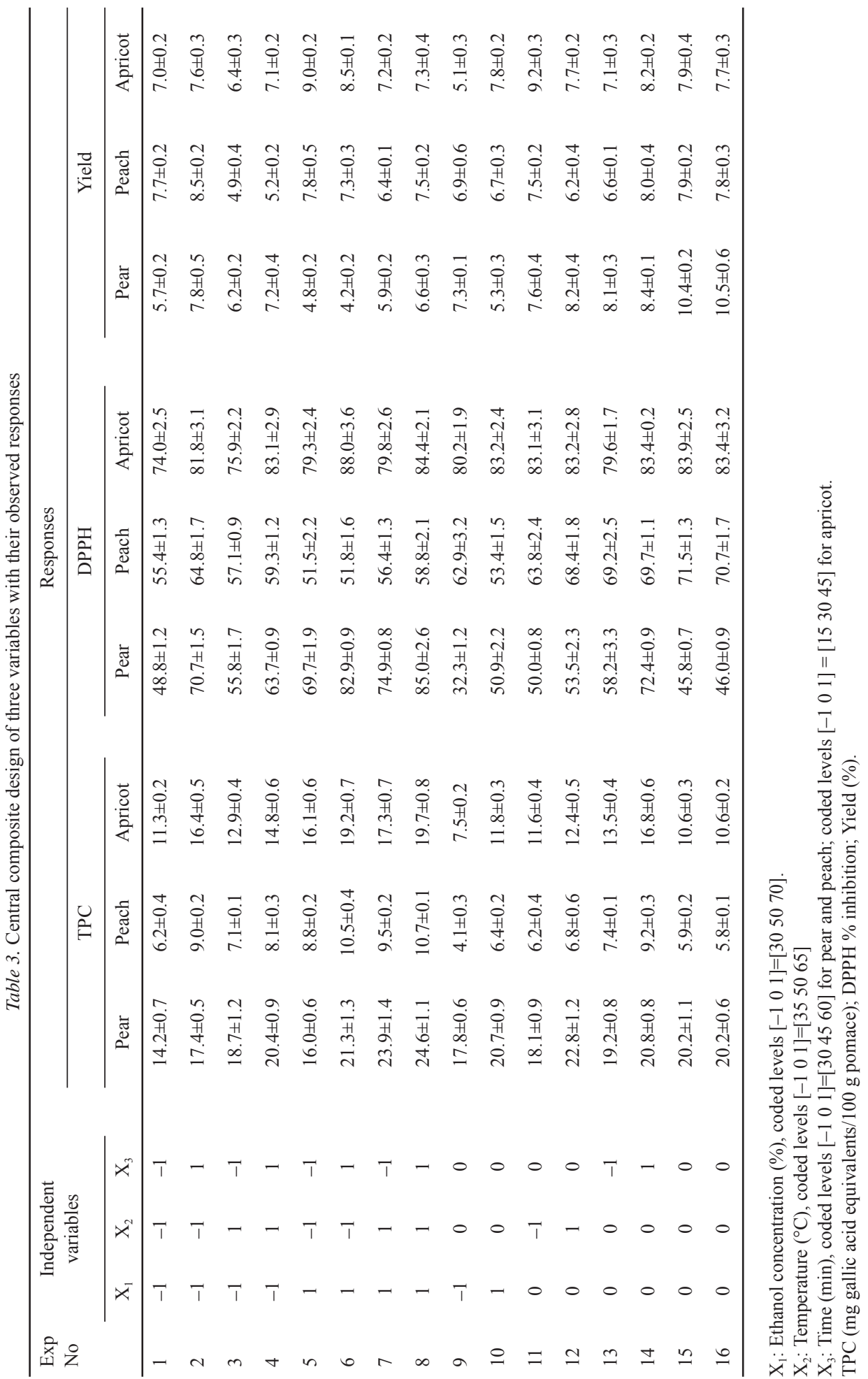



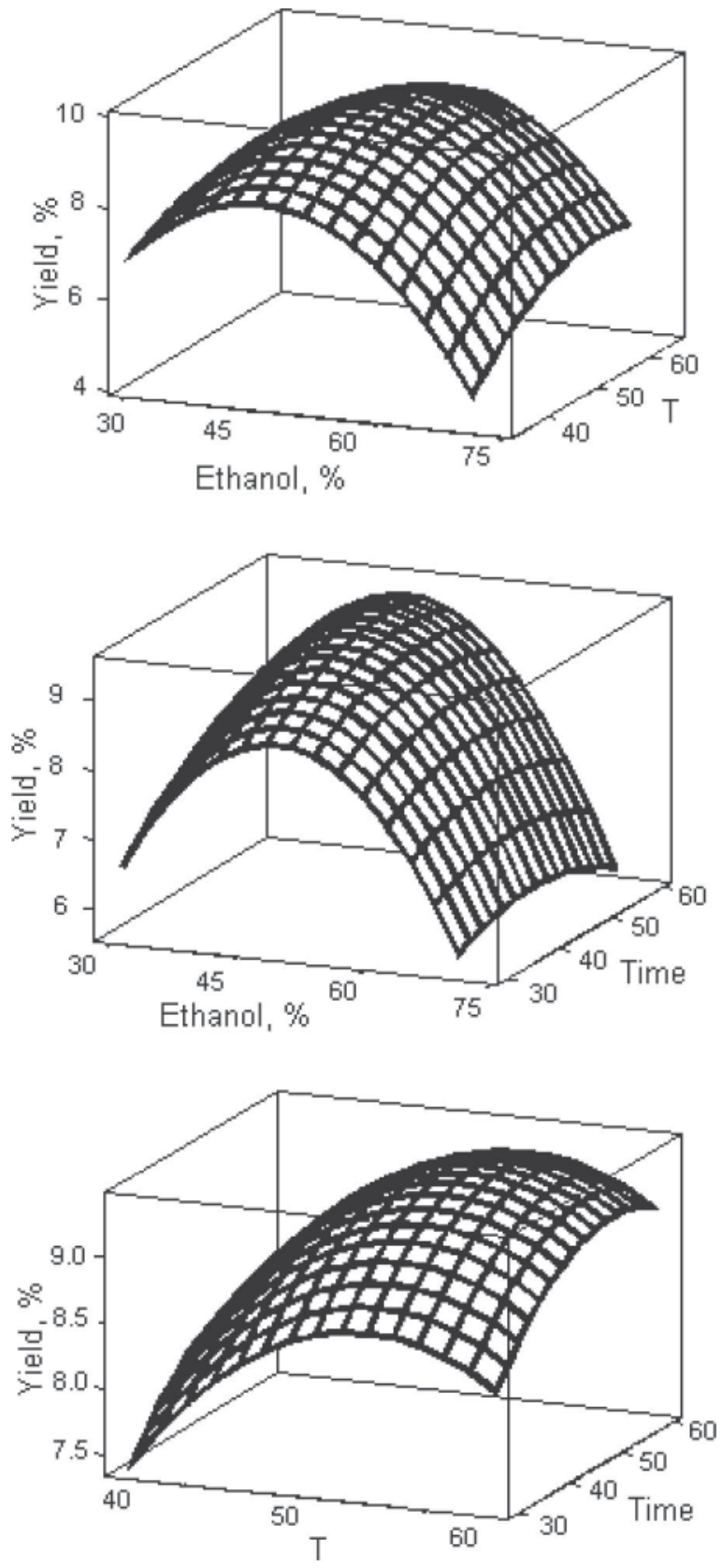

Fig. 1. Response surface plots showing the effects of ethanol percentage, temperature $\left({ }^{\circ} \mathrm{C}\right)$, and time $(\mathrm{min})$ on yield of pear pomace 

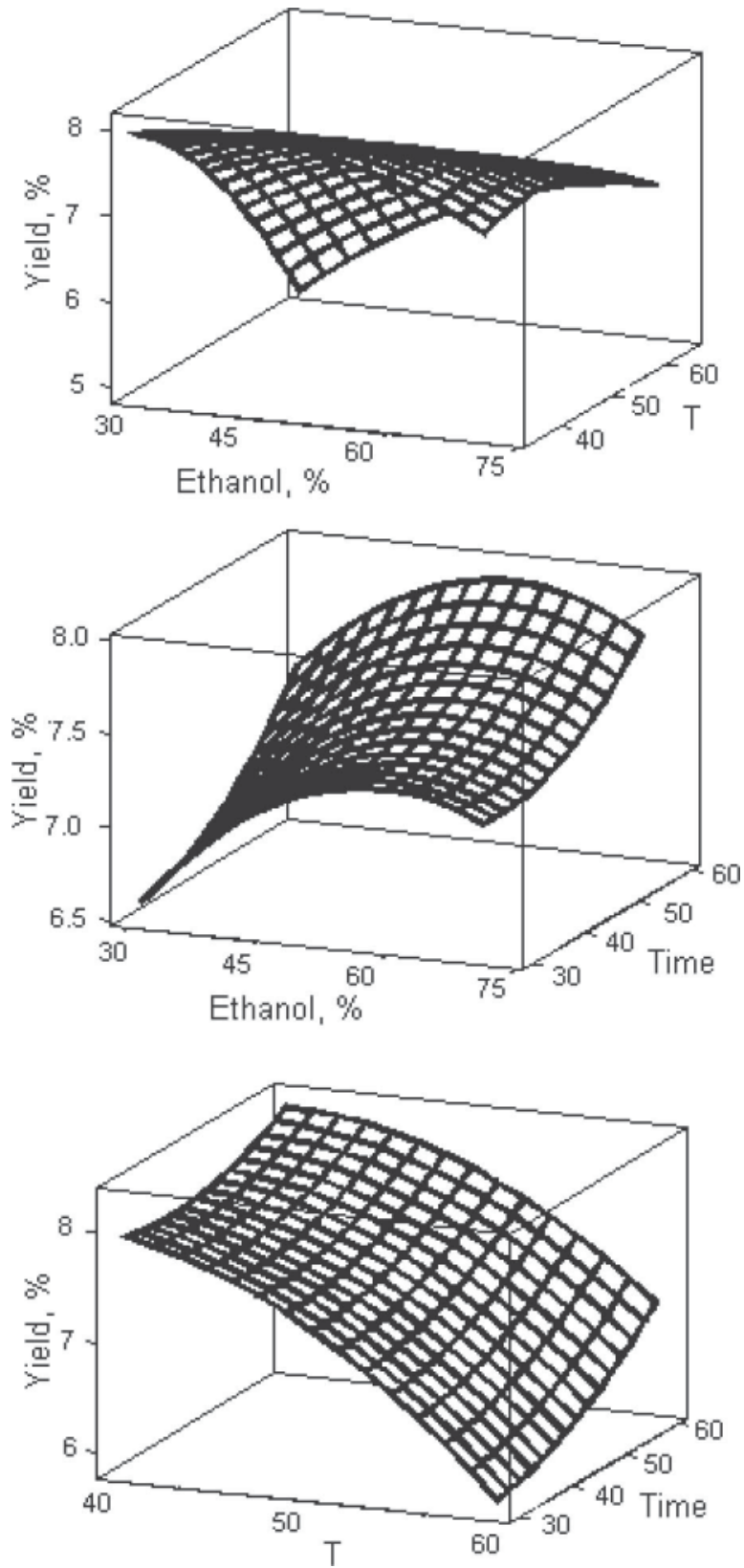

Fig. 2. Response surface plots showing the effects of ethanol percentage, temperature $\left({ }^{\circ} \mathrm{C}\right)$ and time $(\min )$ on yield of peach pomace 

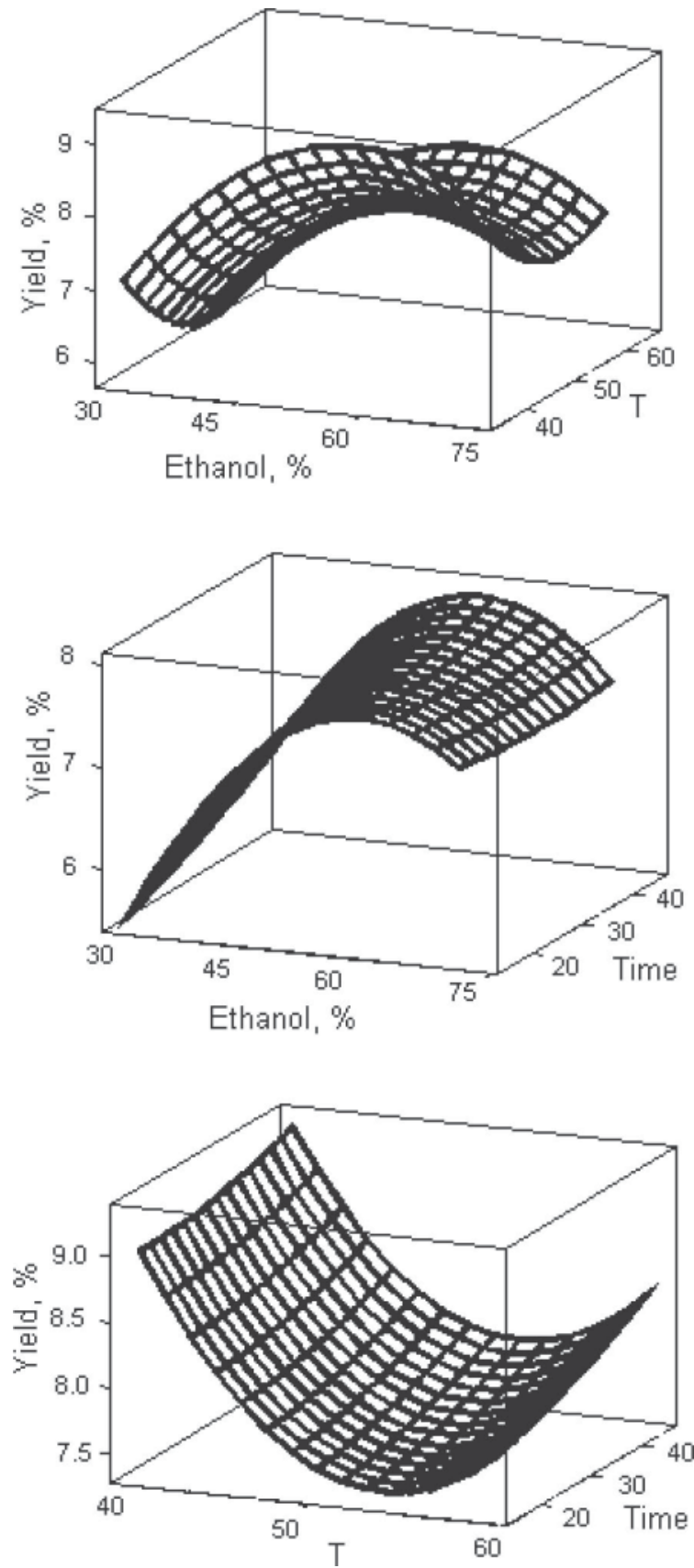

Fig. 3. Response surface plots showing the effects of ethanol percentage, temperature $\left({ }^{\circ} \mathrm{C}\right)$ and time $(\mathrm{min})$ on yield of apricot pomace 


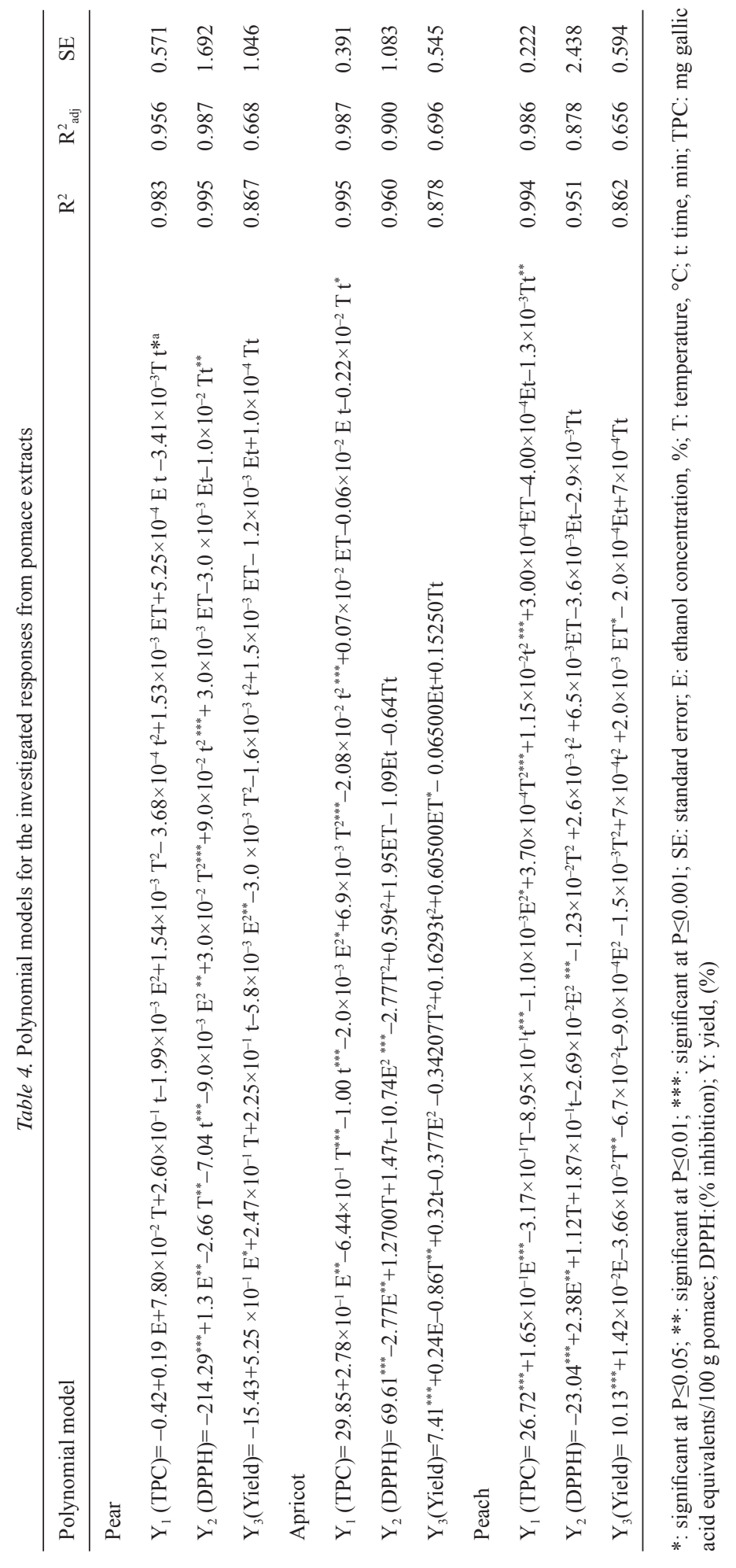




\subsection{Optimal conditions}

The optimal conditions were obtained from the first derivatives of the second-order polynomial equations (Table 4). The optimum UAE conditions for the response variables from extracts are presented in Table 5. The predictive ability of the models was examined by extractions at optimal conditions. Based on results in Tables 3 and 5, experimental conditions for obtaining the extracts with the highest total phenolic contents for industrial applications were solvent percentage of $70 \%$ ethanol, temperature of $35^{\circ} \mathrm{C}$, and extraction time of $60 \mathrm{~min}$ for all residuals.

Table 5. Optimal conditions, predicted and experimental responses for extraction of antioxidants

\begin{tabular}{|c|c|c|c|c|c|}
\hline \multirow[t]{2}{*}{ Responses } & \multicolumn{3}{|c|}{$\begin{array}{l}\text { Optimal } \\
\text { conditions }\end{array}$} & \multicolumn{2}{|c|}{ Maximal values } \\
\hline & Ethanol (\%) & $\mathrm{T}\left({ }^{\circ} \mathrm{C}\right)$ & $\mathrm{t}(\min )$ & Predicted & Actual \\
\hline \multicolumn{6}{|l|}{ Pear } \\
\hline TPC & 70 & 65 & 60 & 24.7 & $24.6 \pm 0.3$ \\
\hline DPPH & 68 & 35 & 60 & 80.1 & $82.8 \pm 1.3$ \\
\hline Yield & 46 & 54 & 53 & 9.3 & $9.6 \pm 0.3$ \\
\hline \multicolumn{6}{|l|}{ Apricot } \\
\hline TPC & 70 & 35 & 45 & 19.3 & $19.2 \pm 0.4$ \\
\hline DPPH & 70 & 35 & 45 & 87.4 & $88.0 \pm 2.1$ \\
\hline Yield & 56 & 35 & 45 & 9.4 & $9.3 \pm 0.1$ \\
\hline \multicolumn{6}{|l|}{ Peach } \\
\hline TPC & 69 & 35 & 60 & 10.4 & $10.4 \pm 0.3$ \\
\hline DPPH & 46 & 50 & 60 & 71.8 & $70.0 \pm 1.9$ \\
\hline Yield & 40 & 35 & 60 & 8.4 & $8.3 \pm 0.2$ \\
\hline
\end{tabular}

TPC (mg gallic acid equivalents/100 g pomace); DPPH (\% inhibition); Yield (\%)

In this work, TPC results were reported as $\mathrm{mg}$ gallic acid equivalents per $100 \mathrm{~g}$ fresh pomaces. Extracts had total phenolic contents (pear, 24.6; apricot, 19.2; and peach, $10.2 \mathrm{mg}$ gallic acid equivalents per $100 \mathrm{~g}$ fresh pomaces) comparable to some fresh fruit such as avocado (21.86), banana (25.55), green grape (23.20), muskmelon (white pulp, 20.36), olive (21.68), peach (27.58), pear (fragrant, 18.65; honey, 11.88; royal, 34.84), and watermelon (red pulp, 24.66; yellow pulp, $18.62 \mathrm{mg}$ gallic acid equivalents per $100 \mathrm{~g}$ fresh weight) (Fu et al., 2011). 


\section{Conclusions}

Increased concern over the safety of synthetic antioxidants like butylated hydroxylanisole (BHA) and butylated hydroxyltoluene (BHT) has led to an increased interest in exploration of effective and economical natural antioxidants. Pear, peach, and apricot by-products could be a good commercial source of chlorogenic acid, caffeic acid, quercetin, flavonoids, and carotenoids and they can be separated and concentrated through extraction process.

\section{References}

Bartnik, D.D., Mohler, C.M. \& Houlinan, M. (2006): Methods for the production of food grade extracts. United States Patent Application 20060088627, April 27.

Bezerra, M.A., Santelli, R.E., Oliveira, E.P., Villar, L.S. \& Escaleira, L.A. (2008): Response surface methodology (RSM) as a tool for optimization in analytical chemistry. Talanta, 76, 965-977.

Brand-Williams, W., Cuvelier, M.E. \& Berset, C. (1995): Use of a free radical method to evaluate antioxidant activity. LWT - Food Sci. Technol., 28, 25-30.

Finkel, T. \& Holbrook, N.J. (2000): Oxidants, oxidative stress and the biology of ageing. Nature, 408, 239-247.

Fu, L., Xu, B.T., Xu, X.R., Gan, R.Y., Zhang, Y., XIA, E.Q. \& LI, H.B. (2011): Antioxidant capacities and total phenolic contents of 62 fruits. Food Chem., 129, 345-350.

Oliveira, A., Pintado, M. \& Almeida, D.P.F. (2012): Phytochemical composition and antioxidant activity of peach as affected by pasteurization and storage duration. LWT - Food Sci. Technol., 49, 202-207.

Salta, J., Martins, A., Santos, R.J., Neng, N.R., Nogueira, J.M.F., Justino, J. \& Rauter, A.P. (2010): Phenolic composition and antioxidant activity of Rocha pear and other pear cultivars. A comparative study. J. Funct. Foods, 2, 153-157.

Schieber, A., Keller, P. \& Carle, R. (2001): Determination of phenolic acids and flavonoids of apple and pear by high performance liquid chromatography. J. Chromatogr. A, 910, 265-273.

Singleton, V.L. \& Rossi, J.A. JR. (1965): Colorimetry of total phenolics with phosphomolybdic-phosphotungstic acid reagents. Am. J. Enol. Viticult., 16, 144-158.

Solis-Solis, H.M., Calderon-Santoyo, M., Gutierrez-Martinez, P., Schorr-Galindo, S. \& Ragazzo-Sanchez, J.A. (2007): Discrimination of eight varieties of apricot (Prunus armeniaca) by electronic nose, LLE and SPME using GC-MS and multivariate analysis. Sensor Actuator B, 125, 415-421.

Virot, M., Tomao, V., Le Bourvellec, C., Renard, C.M.C.G. \& Chemat, F. (2010): Towards the industrial production of antioxidants from food processing by-products with ultrasound-assisted extraction. Ultrason. Sonochem., 17, 1066-1074. 